\title{
Os modelos de organização territorial e gestão das áreas protegidas do litoral de São Paulo com enfoque no Parque Estadual Ilha do Cardoso
}

\author{
The models of territorial organization and management of the \\ protected areas of the São Paulo coast with a focus on the \\ Ilha do Cardoso State Park
}

Los modelos de organización territorial y gestión de las áreas protegidas del litoral de São Paulo con enfoque en el Parque Estadual Isla del Cardoso

\author{
Jéssica de Lima Silva \\ Regina Célia de Oliveira ${ }^{2}$ \\ Universidade Estadual de Campinas, Brasil
}

\section{Resumo}

O presente artigo analisa os modelos de organização territorial e institucional das Áreas Protegidas do Litoral Sul do Estado de São Paulo, com enfoque no Parque Estadual Ilha do Cardoso - PEIC. Apresenta-se considerações sobre a importância da organização dos Mosaicos de Áreas Protegidas do Litoral Sul e o papel do PEIC na Conservação da biodiversidade. São Apresentados aspectos dos

1 Doutoranda pela Universidade Estadual de Campinas- UNICAMP. R. Carlos Gomes, 250 - Cidade Universitária, Campinas - SP, Brasil, 13083-896. jssicalime@gmail.com

2 Professora Doutora do Programa de Pós-Graduação em Geografia da Universidade Estadual de CampinasUNICAMP. UNICAMP. R. Carlos Gomes, 250 - Cidade Universitária, Campinas - SP, Brasil, 13083-896. reginacoliveira@ige.unicamp.br 
Jéssica de Lima Silva, Regina Célia de Oliveira. The models of territorial organization and management of the protected areas of the São Paulo coast with a focus on the Ilha do Cardoso State Park

desdobramentos da institucionalização do Parque e seus reflexos atualmente. As Áreas Protegidas Costeiras sofrem com uma série de pressões de Uso da terra e problemáticas socioambientais. Significativas mudanças ocorreram no Parque nos últimos anos, dentre as quais se destacam as frequentes necessidades que surgiram no esforço de conciliar as estratégias de Manejo e Gestão Participativa com as demandas das populações tradicionais e suas atividades. Assim, as estratégias de manejo, fazem-se necessárias para que os objetivos e funcionalidades desta Unidade de Conservação sejam de fato, efetivos.

Palavras-chave: Áreas Protegidas. Ordenamento Territorial do Litoral Sul de São Paulo. Parque Estadual Ilha do Cardoso.

\begin{abstract}
This article analyzes the models of territorial and institutional organization of the Protected Areas of the South Coast of the State of São Paulo, focusing on the Ilha do Cardoso State Park - PEIC. Considerations are given regarding the importance of the organization of the Mosaics of Protected Areas of the South Coast and the role of the PEIC in the Conservation of biodiversity. Aspects of the unfolding of the institutionalization of the Park and its reflections are presented today. Coastal Protected Areas suffer from a series of land use pressures and socio-environmental issues. Significant changes have occurred in the Park in recent years, among which are the frequent needs that have arisen in the effort to reconcile the strategies of Management and Participatory Management with the demands of the traditional populations and their activities. Thus, management strategies are necessary in order for the objectives and functionalities of this Conservation Unit to be effective.
\end{abstract}

Keywords: Protected Areas. Territorial Planning of the South Coast of São Paulo. Ilha do Cardoso State Park.

\title{
Resumen
}

El presente artículo analiza los modelos de organización territorial e institucional de las Áreas Protegidas del Litoral Sur del Estado de São Paulo, con enfoque en el Parque Estadual Ilha do Cardoso - PEIC. Se presentan consideraciones sobre la importancia de la organización de los Mosaicos de Áreas Protegidas del Litoral Sur y el papel del PEIC en la Conservación de la biodiversidad. Se presentan aspectos de los desdoblamientos de la institucionalización del Parque y sus reflejos actualmente. Las Áreas Protegidas Costeras sufren con una serie de presiones de Uso de la tierra y problemáticas socioambientales. Significativos cambios ocurrieron en el Parque en los últimos años, entre las cuales se destacan las frecuentes necesidades que surgieron en el esfuerzo de conciliar las estrategias de Manejo y Gestión Participativa con las demandas de las poblaciones tradicionales y sus actividades. Así, las estrategias de manejo, se hacen necesarias para que los objetivos y funcionalidades de esta Unidad de Conservación sean de hecho, efectivos.

Palabras clave: Áreas protegidas. Ordenación Territorial del Litoral Sur de São Paulo. Parque Estatal Ilha do Cardoso.

\section{Introdução}

As Áreas Protegidas fazem parte da pauta de conservação da diversidade biológica num cenário global e possuem um papel fundamental na discussão da questão ambiental atualmente. No Brasil, as Áreas Protegidas

208 Revista Geográfica de América Central Nº 61E (3) Especial CLAG Este artículo está bajo una licencia 
Jéssica de Lima Silva, Regina Célia de Oliveira. Os modelos de organização territorial e gestão das áreas protegidas do litoral de São Paulo com enfoque no Parque Estadual Ilha do Cardoso

(intitulam-se Unidades de Conservação - UCs), são consideradas importantes pilares para a redução dos índices de desmatamento, degradação ambiental e comprometimento da biodiversidade restante no País. As áreas protegidas garantem serviços essenciais à humanidade como um todo, sendo o principal deles, a conservação da biodiversidade existente. Estas áreas abrigam também uma grande diversidade étnica inserida no território brasileiro, como populações indígenas e populações tradicionais Caiçaras, Quilombolas, Ribeirinhos, Seringueiros, entre outras.

Há uma série de interesses legítimos sobre as diferentes perspectivas de Usos da Terra destinados às UCs, bem como uma grande variação de atores externos e internos que influenciam as dinâmicas nelas existentes, principalmente no que diz respeito às que estão inseridas no contexto das dinâmicas costeiras.

Um dos aspectos inerentes à discussão sobre ordenamento territorial e ambiental no Brasil é a criação e institucionalização das UCs, consideradas áreas naturais protegidas pelo poder público, que têm por princípio, essencialmente, a conservação da biodiversidade.

A análise sobre as políticas ambientais governamentais, que dispõem acerca das unidades de conservação, contempla uma discussão conceitual do território a partir de várias abordagens (a biológica, física, socioeconômica e cultural). Neste sentido, viabiliza abordar a dimensão da desorganização territorial e dos processos de desterritorialização e reterritorialização, que podem ocorrer com a criação das UCs. Segundo Vallejo (2009):

A criação das unidades de conservação no mundo atual vem se constituindo numa das principais formas de intervenção governamental, visando reduzir as perdas da biodiversidade face à degradação ambiental imposta pela sociedade (desterritorialização das espécies da flora e fauna). Entretanto, esse processo tem sido acompanhado por conflitos e impactos decorrentes da desterritorialização de grupamentos sociais (tradicionais ou não) em várias partes do mundo. ( Vallejo, 2009, p.17)

O conceito de Unidades de Conservação, incorporado hoje ao de áreas protegidas, foi inicialmente postulado nos Estados Unidos da América, quando da criação do primeiro Parque Nacional do mundo: o de Yellowstone, em 1872. Outros países seguiram tal exemplo, como Canadá, Nova 
Zelândia e Austrália. A visitação pública e uso recreativo e turístico das Unidades foram as razões iniciais da criação destas áreas.

A criação dessas áreas ao redor do mundo configura uma importante estratégia de controle e monitoramento do território, visto que estabelece limites e dinâmicas de uso e ocupação específicos de acordo com a área protegida. Este controle e os critérios de uso que normalmente se aplicam às áreas protegidas são frequentemente atribuídos em virtude da valorização e da necessidade de resguardar a biodiversidade existente nessas áreas.

Nesse sentido, as políticas ambientais do Brasil estão balizadas pela classificação preconizada pela IUCN - União Internacional de Conservação da Natureza (1994), que considera não apenas os atributos e características biofísicas das áreas, mas também os objetivos de conservação que elas possam satisfazer.

No Brasil, a discussão internacional sobre áreas protegidas passou a influenciar, de forma significativa, a política brasileira para conservação, em função das transformações estruturais no País durante o governo Vargas, na década de 1930. A industrialização e o crescimento das cidades fez surgir a necessidade de controle e gestão de recursos naturais pelo Estado e, assim, o avanço na política de implantação de áreas protegidas fundamentava-se como questão nacional. Neste contexto, as UCs passaram por várias legislações e disposições ambientais e em 2000 foram, finalmente, incorporadas pela Lei 9985/2000, ao Sistema Nacional de Unidades de Conservação- SNUC- que estabelece diretrizes e normas balizadoras para a institucionalização das Unidades de Conservação no País.

Dentre os significativos avanços desse Sistema, um deles diz respeito à criação de dois grupos de Unidades de Conservação: as Unidades de Proteção Integral e as Unidades de Uso Sustentável.

As Unidades de Conservação têm sido consideradas importantes alternativas em políticas públicas no que tange à proteção da biodiversidade. Porém, conforme coloca Irving (2002) a implantação dos mesmos modelos provenientes de países como Estados Unidos, ampliando a dicotomização sociedade- natureza, vem gerando um quadro de conflitos sociais, culturais e econômicos para as populações que vivem em áreas de inserção dessas As Unidades de Conservação, principalmente quando estão no interior de Parques, na categoria de UC de proteção integral, que representa um exemplo emblemático de cisão sociedade- natureza. 
Jéssica de Lima Silva, Regina Célia de Oliveira. Os modelos de organização territorial e gestão das áreas protegidas do litoral de São Paulo com enfoque no Parque Estadual Ilha do Cardoso

Para Diegues (2004), é fundamental enfatizar que a transposição do "modelo Yellowstone", - originado em países industrializados e de clima temperado - para países subdesenvolvidos, cujas florestas remanescentes foram e continuam sendo, em grande parte, habitadas por populações tradicionais, está na base não só de conflitos, mas de uma visão equivocada de áreas protegidas.

Um exemplo desta questão ocorre ao longo de toda a extensão do Litoral do estado de São Paulo, onde é notório não apenas problemáticas apontadas na direção de conflitos e impasses fundiários entre populações tradicionais e a Legislação vigente acerca das áreas protegidas, como também severos agravantes como as diversas pressões por uso em razão do histórico de longa data de conflitos relacionados ao Uso da Terra e pressões econômicas oriundas do desenvolvimento do turismo, especulação imobiliária, aumento da densidade demográfica, destinações econômicas e processos produtivos diferenciados que atuam fortemente nas Zonas Costeiras e que atentam para o surgimento de condicionantes que agravam a vulnerabilidade ambiental e fragilidade dos ecossistemas presentes nestas áreas, chamando atenção para a necessidade de estudos e, sobretudo, planejamento e gerenciamentos adequados destas áreas, por parte das Instituições públicas e também da sociedade civil.

A Identificação e espacialização dos níveis de conflitos existentes nas áreas protegidas, tanto nas categorias de Proteção Integral como de Uso Sustentável, sejam no âmbito territorial da criação e implantação dos Parques, sejam eles em relação aos conflitos externos e internos envolvendo a sobreposição das UCs nas áreas onde habitam populações tradicionais, as esferas públicas do poder (pautadas nas questões institucionais), as diferentes pressões por Uso e destinações da Terra podem resultar em indicativos persistentes de que as formas e esferas de intervenção nas UCs podem ser conduzidas de maneira a considerar as perspectivas e participação dos atores ali existentes, podendo considerar propostas de gerenciamentos mais participativos e menos centralizadores.

Deste modo, se fazem necessárias as discussão e análise sobre a funcionalidade das Unidades de Conservação e se de fato, estas cumprem um papel efetivo de conservação da biodiversidade. Conforme coloca Vallejo (2009) trata-se, portanto, de um tema relevante para a reflexão e exercício sobre o ordenamento territorial dentro de uma perspectiva de sustentabilidade socioambiental. 


\section{Estrutura Metodológica}

Para a construção da análise e diagnóstico da disposição das áreas protegidas e as variáveis de atores, instrumentos de conflitos e disposições legais que coexistem nestas áreas, a metodologia está atrelada à proposta metodológica de Análise Funcional da Paisagem, de Rodriguez (2010). O pressuposto central dessa proposta é baseado nas discussões de Sotchava (1977 e 1978) e fundamenta-se nos princípios da análise sistêmica, ou seja, numa análise integrada dos componentes antrópicos e naturais que considera o estudo integrado dos fenômenos socioambientais e elementos geoecológicos, capazes de fornecer subsídios para que seja possível compreender os diferentes níveis de complexidade no que diz respeito à organização dos atores que coexistem no PEIC, com vistas ao entendimento do ordenamento territorial e estratégias de manejo construídas por tais atores.

Deste modo, são capazes de fornecer instrumentos que contribuam ao entendimento de gestão no contexto o qual a Unidade de Conservação em questão se insere, podendo assim, respaldar as discussões decorrentes de conflitos de Usos da Terra e das relações institucionais que ocorrem nestas UC.

De acordo com Rodriguez (2010), a abordagem da análise funcional da Paisagem, passou a ter notoriedade a partir da década de 1970, quando foram introduzidos os métodos sistêmicos e quantitativos e desenvolvida a Ecologia da Paisagem. O funcionamento da Paisagem constitui um processo mediante o qual cumprem-se funções, ações à determinado trabalho. É um processo de intercâmbio de substâncias e energia que ocorre na interação dos componentes na própria paisagem com o exterior.

Como aponta Rodriguez (2010), a análise sistêmica se baseia no conceito de paisagem com um "todo sistêmico" em que se combinam a natureza, a economia, a sociedade e a cultura, em um amplo contexto de inúmeras variáveis que buscam representar a relação da natureza como um sistema e dela com o homem. Os sistemas formadores da paisagem são complexos e exigem uma multiplicidade de classificações que podem, segundo o autor, enquadrar-se perfeitamente em três princípios básicos de análise: o genético, o estrutural sistêmico e o histórico, que se fundem numa classificação complexa.

O princípio estrutural no estudo das paisagens, fundamenta que a paisagem, possui índices e as propriedades dos objetos materiais estruturais. A organização da mesma está relacionada com o nível de estrutura, 
sendo que a estrutura da paisagem reflete a organização sistêmica de seus elementos funcionais e também as regulações que determinam sua essência, sua morfologia e sua integridade, de modo que a estrutura consiste num elemento relativamente estável e inerente à organização da paisagem enquanto sistema.

A discussão da análise da paisagem através do enfoque de funcionalidade, emprega recursos de análise também voltados para áreas protegidas pautados na otimização do plano de uso, manejo e gestão das unidades territoriais a que se propõem a trabalhar.

\section{Contextualização da Área de Estudo}

O Parque Estadual Ilha do Cardoso- PEIC tem uma área de $151 \mathrm{~km} 2$ e localiza-se no extremo Sul do litoral paulista, na divisa com o Estado do Paraná. Está situado entre as coordenadas 48005 ' 42" W, 25003 '05' S e 480 53' 4811 W, 250 18' 18' S, separado do continente pelo canal de Trapandé. As vias de acesso para a Ilha saem pelo município de Cananéia e Ilha Comprida: (figura 1). O PEIC faz parte de um conjunto de Unidades de Conservação existentes na Região do Vale do Ribeira, Sul do Estado de São Paulo. Presentes na bacia do Rio Ribeira de Iguape, essas Unidades fazem parte de um sistema criado pela SMA-SP (Secretaria de Estado do Meio Ambiente do Estado de São Paulo), além da participação do governo federal, por meio do MMA (Ministério do Meio Ambiente), IBAMA (Instituto Brasileiro do Meio Ambiente) e CONAMA (Conselho Nacional do Meio Ambiente). 
Figura 1: Localização do Parque Estadual Ilha do Cardoso

LOCALIZAÇÃO DA ILHA DO CARDOSO - SP

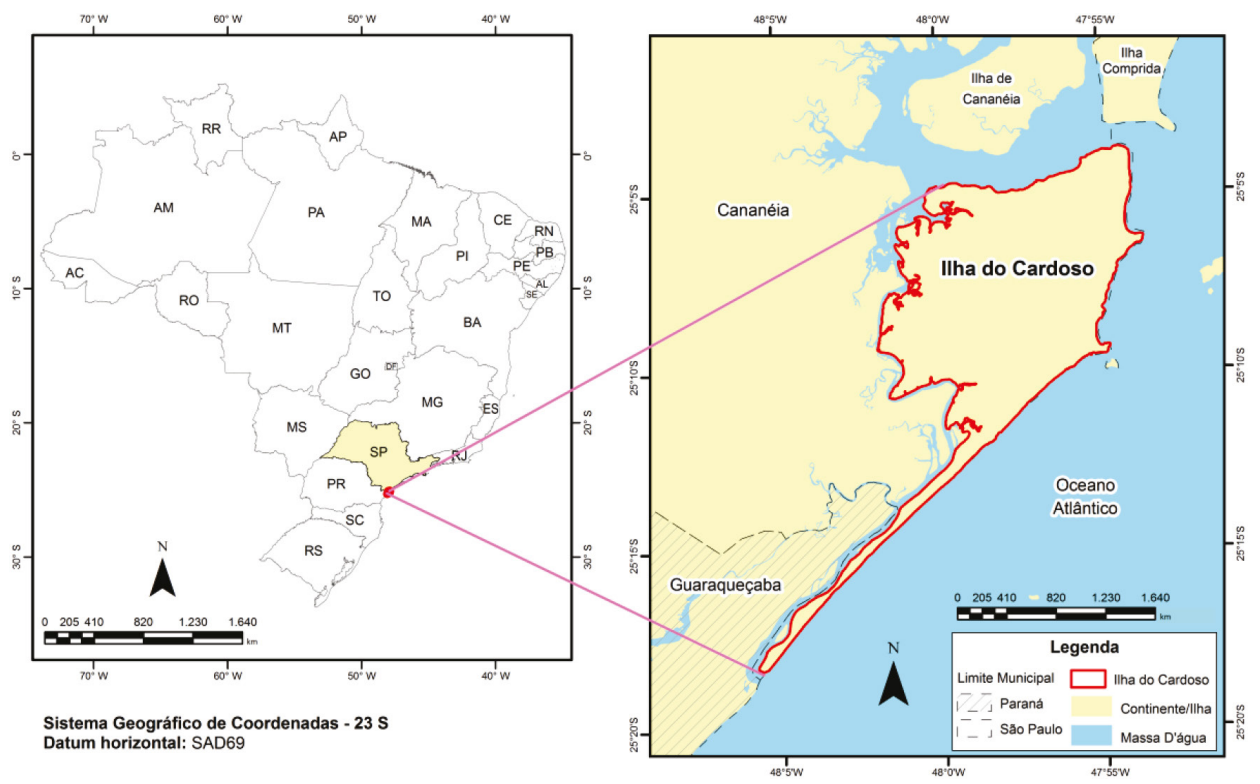

Fonte: Jéssica de lima Silva (2017).

O Parque Estadual Ilha do Cardoso está inserido no complexo de Unidades de Conservação do Vale do Ribeira, conhecido também como Mosaico de áreas protegidas. O Vale do Ribeira, localizado na região sul do estado de São Paulo, constitui a Região mais preservada do estado de São Paulo. A região do Médio Ribeira é marcada por transição morfológica entre as Serranias e Planícies, apresentando suavização aparente das declividades médias dos morros, maior abrangência dos terraços e presença de vários afluentes significativos do Rio Ribeira como o Jacupiranga e Juquiá e onde situam-se municípios como Eldorado, Sete Barras, Juquiá, Jacupiranga e Registro.

O conjunto dessas UCs está estabelecido em áreas naturalmente mais preservadas do Estado de São Paulo e da bacia hidrográfica do Ribeira de Iguape. De acordo com Ross (2009), esse conjunto de UCs faz parte de um Mosaico de áreas protegidas do Estado de São Paulo, que abrange desde a faixa costeira de Peruíbe em direção ao sul, até os limites com o 
Jéssica de Lima Silva, Regina Célia de Oliveira. Os modelos de organização territorial e gestão das áreas protegidas do litoral de São Paulo com enfoque no Parque Estadual Ilha do Cardoso

Estado do Paraná, e ao longo de toda área serrana que contorna a baixada do baixo Ribeira. Organizam-se em forma de arco pelas Serras do Mar, Paranapiacaba, médio vale do Ribeira estendendo-se até o alto dos rios Turvo e Jacupiranga, e encerram-se no litoral sul do Estado de São Paulo, na Ilha do Cardoso, nos limites com o Estado do Paraná.

Esse Mosaico de áreas protegidas localizado na bacia hidrográfica do Ribeira de Iguape distribuí-se pelas áreas de maior fragilidade ambiental, sendo aquelas com relevos montanhosos de um lado e os relevos de planície costeira do outro lado:

Essas áreas são as mais preservadas no território da bacia e de maior riqueza de fauna e flora, pois congregam o pouco que resta no Brasil da Mata Tropical Atlântica, que ocupa escarpas e morro da área serrana, bem com as matas residuais de restinga e mangues, que têm na região costeira, sul do Estado de São Paulo, extensas áreas contínuas muito preservadas. (Ross, 2009, p36).

O Mosaico desempenha fundamental importância para a conservação e preservação ambiental, tanto dos ecossistemas costeiros como da rica biota do ecossistema serrano representada pela mata tropical atlântica.

Esses ambientes são de interesse ecológico em função de sua riqueza em biodiversidade e de seu importante papel como banco genético. As áreas delimitadas pelas unidades de conservação ambiental são, portanto, de absoluto interesse à sua manutenção do status quo, com a preocupação de impedir os avanços de sua ocupação, diante das fortes pressões das áreas ocupadas dos estornos, em função dos efeitos de borda. (Ross, 2009, 36).

Segundo o autor, com objetivos diversos e graus diferenciados de restrição, as UCs podem dispor de determinações rígidas que impedem a utilização integral de seus recursos naturais. Podem também ser mais flexíveis.

São, portanto, mais de 90 quilômetros de extensão em continuidade do litoral, sendo ele recortado por baías, deltas e estuários de rios. Na fachada atingida diretamente pela ação marinha é marcada pela presença de inúmeros costões rochosos e ilhas continentais como a Ilha do Bom Abrigo e Ilha do Castilho (ambas possíveis de serem avistadas da Ilha do Cardoso).

Em relação ao histórico de ocupação, conforme Gouveia (2010) o Vale do Ribeira constitui hoje uma das áreas de menor densidade de 
ocupação, e maior carência de infraestrutura de todo o estado, entretanto sua porção inferior configura o primeiro local por onde os colonizadores do estado de São Paulo estabeleceram seus núcleos e, também, por onde conseguiram efetuar as primeiras penetrações para o interior do continente.

É, portanto, no Vale do Ribeira, onde se concentra o maior número de Unidades de Conservação do Estado de São Paulo. Em 1998, recebeu o título da Organização das Nações Unidas para a Educação, Ciência e Cultura (UNESCO) como Patrimônio Histórico e Ambiental da Humanidade, além disso, a região também integra as Áreas Piloto da Reserva da biosfera da Mata Atlântica.

\section{Estrutura Teórico- Conceitual}

Um primeiro ponto a que se pode atentar para a questão da análise das Unidades de Conservação no âmbito político e territorial, diz respeito à delimitação que elas recebem. A delimitação de UC é considerada (do ponto de vista da conservação do seu potencial geoecológico) em função do seu tamanho, pois geralmente, as grandes unidades, em teoria comportam mais espécies do que as menores em tamanho.

Conforme atenta Vallejo (2009), o estudo da territorialidade no contexto das Unidades de Conservação é da mais alta importância, inclusive na definição da extensão geográfica mínima necessária à conservação das espécies e, também, para o entendimento dos processos que têm levado à sua desterritorialização. O contexto de criação das foi acompanhado de severas críticas principalmente decorrentes da falta de iniciativas realmente eficazes de consolidação territorial pelas esferas públicas governamentais responsáveis.

Inicialmente, as UCs propostas no Brasil ${ }^{3}$ não consideraram a legitimidade do padrão de política de conservação adotado, isso se reflete no âmbito federal, mas também estadual. Elas foram resultado de um processo arbitrário de tomada de decisões, cujos governos partiam do pressuposto de que a conservação da biodiversidade remanescente não seria um direito reivindicado pelas comunidades tradicionais que vivem nos limites territoriais de suas esferas e níveis de atuação. Segundo Ferreira (2001):

3 Importante lembrar que o termo unidade de conservação é restrito ao Brasil e refere-se a determinadas categorias específicas de áreas protegidas, previstas pela Lei n.9.985/2000 a qual estabelece o SNUC. Internacionalmente, o termo generalizado e difundido é áreas protegidas.

216 Revista Geográfica de América Central No 61E (3) Especial CLAG Este artículo está bajo una licencia e-ISSN 2215-2563 • Julio-diciembre 2018 • pp. 207-235 Atribución/Reconocimiento-NoComercialDoi: http://dx.doi.org/10.15359/rgac.61-3.11

CompartirIgual 4.0 Internacional 
Essa tarefa de compatibilizar as exigências internacionais de conservação com os problemas criados a partir do congelamento econômico de um território imenso, populoso, industrializado e urbanizado foi sempre dispendiosa, conflituosa e tecnicamente muito difícil, exceto nos casos onde a própria especulação imobiliária exigiu que as terras fossem mantidas intatas. Nesse contexto e na medida em que as UCs brasileiras foram sendo implantada, a ação cotidiana das instituições publicas colocou seus agentes em uma situação social de confronto com os moradores dessas áreas sob proteção legal. Propostas de conservação formuladas em gabinetes fechados, debatidas e referendadas muitas vezes em fóruns internacionais, no momento de serem implementadas, foram altamente politizadas, mobilizando diversos atores em torno de diversas arenas; outros tiveram que rever posições e conceitos e, principalmente os moradores, em sua maioria sem uma prévia experiência importante de participação política, foram repentinamente e inusitadamente lançados a uma situação de ator. (Ferreira ,2001, p. 21).

Ao se dedicar à natureza, o território político e de poder está mais vinculado à proteção do que ao convívio entre todos os elementos da natureza presentes em uma UC e a complexidade existente entre os mesmos. Permanece-se ainda sob uma visão ecológica (originalmente conhecida como "deep ecology" - ou ecologia profunda), devendo-se proteger os espaços nos quais ainda há significativa biodiversidade e que não foram degradados/depredados pela sociedade urbano-industrial .

Nesse contexto podem ocorrer generalizações, colocando num mesmo patamar de responsabilidade pela degradação dos recursos naturais tanto a sociedade urbano-industrial capitalista, quanto àquelas populações tradicionais que de fato possuem uma relação diferenciada com a "natureza" da qual, inclusive, depende. As restrições em áreas protegidas muitas vezes causam conflitos que podem levar à desterritorialização dos espaços, gerando novas territorialidades nos grupos que são proibidos de permanecerem nessas áreas, além da perda potencial das identidades paisagísticas das populações tradicionais.

Um dos grandes objetivos da criação de áreas protegidas é a manutenção de áreas naturais em seu estado menos alterado possível. As políticas de proteção da natureza se fundamentam na estratégia de criação das Unidades de Conservação, como um caminho efetivo para conservação da biodiversidade. São tidas como importantes elementos para a continuidade 
da evolução natural e em diversas partes do mundo, consideradas único meio possível para uma futura restauração de processos ecológicos e espécies que não sobreviveriam em áreas com grande interferência humana.

As áreas protegidas são conceituadas pela IUCN como "uma área de terra e/ou mar especialmente dedicada à proteção e manutenção da diversidade biológica e de seus recursos naturais e culturais associados e manejados através de instrumentos legais ou outros meio efetivos (IUCN, 1994).

No decorrer da história brasileira, muitas vozes de manifestaram contra a exploração predatória e pensamento utilitarista com respeito aos recursos naturais. Ao longo do século XIX, a preocupação de muitos intelectuais se consolidou, José Bonifácio de Andrade teve um papel de destaque na condenação dessa atitude predatória. A importância dos recursos naturais para a construção nacional foi a questão central de sua motivação, visto que esses recursos representavam o grande trunfo que possibilitaria o progresso do País e portanto, deveriam, desde um primeiro momento, ser utilizados de forma inteligente.

O Brasil chegou à década de 1990 com categorias plurais de áreas protegidas como política de conservação ambiental, ao passo que também se firmava em nível internacional, um consenso em torno da importância da proteção da biodiversidade e das paisagens nativas. Drummond et al (2010) atenta que os diferentes tipos de UCs nasceram a partir de diferentes fatores, inclusive a sintonia de cientistas e administradores com as mudanças no panorama mundial da conservação ambiental, a ampliação do interesse social na questão, assim como as pressões internacionais e a concorrência entre organismos e gestores e suas diferentes políticas. Porém, eram necessárias ainda, leis e normatizações de gestão que garantissem a efetividade e a pluralidade de categorias, de modo que a situação exigia um maior esforço de sistematização.

Essa dificuldade de sistematização na criação e gerenciamento das UCs no Brasil se expressou, sobretudo, num longo trâmite, percorrendo toda a década de 1990 até corroborar na proposta de Lei 9.985/2000 que estabelece o Sistema Nacional de Unidades de Conservação - SNUC.

Depois de oito anos tramitando no Congresso Nacional, marcando um longuíssimo processo de negociações, em julho de 2000, o então vice-presidente da República Marco Maciel, sancionou finalmente, embora com vetos, a Lei $\mathrm{n}^{\circ}$ 9.985, instituindo assim, o SNUC. Sobre a 
Jéssica de Lima Silva, Regina Célia de Oliveira. Os modelos de organização territorial e gestão das áreas protegidas do litoral de São Paulo com enfoque no Parque Estadual Ilha do Cardoso

problemática envolvendo as populações tradicionais em UCs que foi um dos pontos mais conflituosos durante os longos anos de debate e propostas, Ferreira (2001) contribui dizendo que:

Alguns vetos eram previsíveis, como os que se referem à definição de $p o$ pulação tradicional, e o parágrafo que pressupunha a necessidade de lei específica para a criação de UCs. [...] Já o artigo que propunha a reclassificação de UCs de uso indireto em virtude da presença de população tradicional em seu interior, foi vetada por reivindicação de setores do IBAMA e de ambientalistas refratários à presença humana em UCs. Com isso, as populações que habitam hoje UCs consideradas de proteção integral, depois de sua regulamentação, terão que ser indenizadas e reassentadas pelo poder público. (Ferreira, 2001, p.42)

O SNUC foi estabelecido baseado fundamentalmente nos princípios da IUCN e CDB, constituindo-se das variadas UC federais, estaduais e municipais. Ele possui 14 objetivos principais, dentre eles, encontram-se os de garantir a diversidade biológica, preservando espécies, restaurar e preservar ecossistemas, proteger os diferentes recursos (de natureza geológica, geomorfológica, espeleológica, arqueológica, paleontológica e cultural) promovendo educação, recreação e turismo ecológico, protegendo os recursos necessários à subsistência das populações tradicionais e, sobretudo, promovendo o desenvolvimento sustentável de fato.

O SNUC estabelece que as comunidades tradicionais em UC serão permitidas na categoria de Uso Sustentável e em três tipos de UC, sendo elas: APA; Reserva Extrativista (REx) e Reserva de Desenvolvimento Sustentável (RDS). São estabelecidos quatro critérios sobre os objetivos que devem conter nas UC, tanto de Proteção Integral quanto de Uso Sustentável. Sendo 1- Objetivos primários; 2- Objetivos Secundários; 3- Complementar e por fim- Não aplicável. No Caso das UCs citadas acima, a APA e a REx permitem comunidades tradicionais como objetivos secundários, já a RDs permite como objetivos primários.

Nesse contexto, Diegues (2008) aponta que o processo de regularização fundiária nas UCs apresenta uma série de impasses dado que as populações tradicionais na maioria das vezes não possuem título de dominialidade que comprove a posse da propriedade. Simultaneamente não raro o Estado é obrigado a pagar indenizações milionárias àqueles que 
se estabeleceram nas UCs anteriormente à sua criação, mas que não possuem a condição de moradores tradicionais, na maior parte das vezes sendo agentes ligados à especulação imobiliária. No estado de São Paulo, são comuns exemplos desse tipo nas UCs do Litoral Norte e Vale do Ribeira.

Na configuração político - territorial do histórico das áreas protegidas no Brasil, existe uma visão conflitante entre o espaço público e o espaço das populações tradicionais, segundo perspectivas distintas como afirma Diegues (2008):

A do Estado, representando os interesses das populações urbano-industriais, e das sociedades tradicionais. Na verdade, o que está implícito é que estas deveriam "sacrificar-se" para dotar as populações urbano-industriais de espaços naturais, de lazer e contato com a natureza selvagem (que é um grande mito moderno). Ou ainda, segundo, uma versão mais moderna dos objetivos das áreas naturais protegidas (estabelecidas pelas IUCN, CBD, SNUC) de uso restrito: proteger a biodiversidade. (Diegues, 2008, p.12)

Adicionalmente vem crescentemente sendo ecoados os questionamentos sobre processos de privatização das unidades de conservação, haja vista que se tornam áreas cada vez mais valorizadas e visadas face crescente cerceamento dos ecossistemas naturais com a crescente ampliação dos quadros urbano-industrial e das fronteiras agrícolas. Talvez um dos exemplos mais notáveis neste sentido sejam as propostas de concessão das Florestas Nacionais (Flonas), como apontado por Ab 'Saber (2005).

A Lei $n^{\circ} 411.2884 / 2006$, que dispõe sobre a gestão de florestas públicas para produção sustentável, tem a finalidade precípua de compatibilizar a conservação ambiental com a exploração sustentável das florestas através da concessão das mesmas para corporações privadas, de modo que se transfira à iniciativa privada a responsabilidade por uma pretensa exploração sustentada e conservação das florestas. No manifesto elaborado à época contra o projeto de Lei, Ab'Saber (op.cit.) considerava inadequado tal concessão de Flonas para iniciativa privada:

Essas flonas foram organizadas quando o manto florestal da Amazônia ainda era muito bem preservado. Então isolaram-se algumas áreas para se pensar mais tarde sobre a possibilidade de fazer uma silvicultura seletiva tirando um pouco de proveito delas. Acontece que 20,30 anos depois deste quadro de 
preservação integrada, abriu-se um enorme espaço fora dessas Flonas. Houve uma degradação conectada ao longo de rodovias, de ramais, de sub-ramais, de espinhelas de peixe. E, na medida em que foram estabelecendo pequenas ou grandes fazendas do tipo agropecuário, ou apenas uma experiência qualquer, sem nenhum conhecimento da resposta do solo degradado, evidentemente que as flonas agora constituem reservas de biodiversidade. (Ab'Saber, 2005, p.7)

Pesquisadores e ambientalistas que se manifestam contra tais concessões, questionam que embora não se conceda formalmente a posse da terra, os períodos amplos demais das concessões (que podem ser por décadas), na prática fazem com que se estabeleça relações orgânicas dos grupos vencedores das licitações com as áreas destinadas à concessão. E nesse contexto, é conhecida a fragilidade institucional brasileira, e o quanto o quadro estatal muitas vezes sucumbiu à pressão de grandes grupos econômicos, como argumenta Ab'Saber anteriormente citado.

\section{Resultados}

A Ilha do Cardoso foi instituída como Parque Estadual através do Decreto Estadual No 40.319/62. Há registros de populações desde 1502, quando a Ilha recebeu a expedição exploratória comandada pelos portugueses Gaspar de Lemos e Américo Vespúcio, que tinham a missão de fixar o marco do Tratado de Tordesilhas na praia de Itacuruçá (hoje pertencente ao núcleo Perequê) em frente à ilha do Bom Abrigo .

O PEIC se enquadra na categoria de UCs de Proteção Integral, não sendo juridicamente permitida a presença de populações humanas residindo no interior do Parque, mas que ainda permanecem no mesmo respaldadas pelo art. $42^{\circ}$ da Lei $n^{\circ} 9.985 / 2000$ a qual estabelece o SNUC, onde é previsto a permanência de populações tradicionais até que ocorra a sua remoção para áreas relativamente compatíveis.

Entre as décadas de 1960 e 1980, o turismo e a especulação imobiliária passaram a exercer uma violenta pressão sobre as terras das comunidades caiçaras, principalmente em função do potencial turístico do local. A criação do parque proibiu a venda de propriedades para turistas e veranistas. Em 1972, a Fazenda do Estado de São Paulo ajuizou a ação discriminatória na área do PEIC, objetivando separar as terras devolutas das eventuais terras particulares existentes. 
Muitos moradores que acabaram cedendo a essa especulação, por se sentirem pressionados ou temendo represálias venderam seus lotes, consequentemente perderam o direito de permanecerem no parque e tiveram suas casas demolidas ao longo dos anos. Além da ameaça iminente pela especulação imobiliária na época, a ação intimidadora da Polícia Florestal junto ao Instituto Florestal responsável, pela direção e gestão do PEIC na época, configurou um quadro de caos e desinformação das comunidades caiçaras, acelerando o processo de migração das mesmas. Muitas famílias saíram do Parque e nunca foram indenizadas pelo fato. Essa condição ocasionada no PEIC também se verificava em várias outras partes do Vale do Ribeira, segundo Diegues (1996):

A transformação de parte considerável das comunidades tradicionais em UCs de proteção integral continuou promovendo consequências graves no modo de vida das populações caiçaras. No início, algumas dessas áreas conseguiram frear até certo ponto a especulação imobiliária, mas depois, com a proibição de fazer roça, tirar madeira para canoas, moradia, instrumentos de trabalho, reformar as moradias e escolas, essas comunidades tradicionais tiveram seus direitos civis seriamente ameaçados e em vários casos, violados. Não tendo documento de propriedade, foram consideradas posseiros e obrigadas a deixar seus territórios (sem direito à indenização) para não perecer. (Diegues , 1996, p. 12):

A criação das UCs no Vale do Ribeira não fugiu à regra no PEIC. Quando a criação do Parque ocorreu, foi feita na ausência da participação e ciência das populações tradicionais sobre a criação de políticas restritivas no local em que viviam. Na década de 1980, os veranistas e as populações tradicionais já estavam sobre o impasse de permanecer ou não no Parque e assim como em 1962, faltavam esclarecimentos sobre as condições de permanência.

A população tradicional residente é composta de Caiçaras. Até a década de 2000, a população tradicional caiçara estava distribuída entre os núcleos Itacuruçá e Perequê, Marujá, Enseada da Baleia, Cambriú, Vila Rápida e Pontal do Leste e ocupavam cerca de $5 \%$ da extensão total da Ilha. Através da resistência das comunidades, uma parte delas continuou residindo no local, mas o número de comunidades caiçaras diminuiu no Parque, principalmente nas décadas de 1970 e 1980. 
Quando houve a criação do Parque, o número estimado era de 500 famílias no interior da Ilha, hoje, o número é cerca de 120 famílias entre todos os núcleos. Há também um grupo indígena Guarani Mbya, com cerca de 20 integrantes atualmente, que em 1990 foram morar no PEIC, considerados um grupo intermitente, que se locomove entre as áreas protegidas do Vale do Ribeira.

Há ainda alguns casos de veranistas que residem sazonalmente no PEIC, sobretudo em meses de alta temporada. Porém, principalmente a partir dos anos 2000, tramitam na esfera judicial várias Ações Discriminatórias reivindicando a demolição das residências destes veranistas. Essas Ações Discriminatórias pelo Estado fazem parte dos projetos de regularização fundiária do PEIC, previstas no Plano de Manejo do mesmo.

Segundo Milanelo (1992), até a criação do Parque, a maioria dos moradores sobrevivia da pesca artesanal (redes pequenas, gerival, cerco, redes de espera e lançamento). A agricultura era uma atividade igualmente importante, mas que do ponto de vista de opção como atividade de subsistência dos moradores, deixou de ser viabilizada e autorizada no decorrer das décadas de 1960 em diante.

O Conselho Gestor da Fundação Florestal que administra o Parque considera que a ocupação no PEIC não possui um caráter homogêneo, variando ao longo do Parque. A área que possui as comunidades mais densamente povoadas é o núcleo Marujá, que contempla 56 famílias e o Perequê, que somados aos núcleos Itacuruçá e Cambriu, somam 30 famílias, a Enseada da Baleia, com 5, Vila Rápida, com 4 famílias e Pontal do Leste com 6 famílias.

Os núcleos Marujá, Itacuruçá - Perequê, respecti-vamente, são os mais expressivos quanto ao oferecimento de atividades turísticas. O núcleo Enseada da Baleia também promove atividades turísticas ainda que com menor intensidade. Os núcleos Cambriú, Vila Rápida e Pontal do Leste, vivem fundamentalmente da atividade pesqueira (Figura 2). 
Jéssica de Lima Silva, Regina Célia de Oliveira. The models of territorial organization and management of the protected areas of the São Paulo coast with a focus on the Ilha do Cardoso State Park

Figura 2 - Mapa de Zoneamento do Parque Estadual Ilha do Cardoso
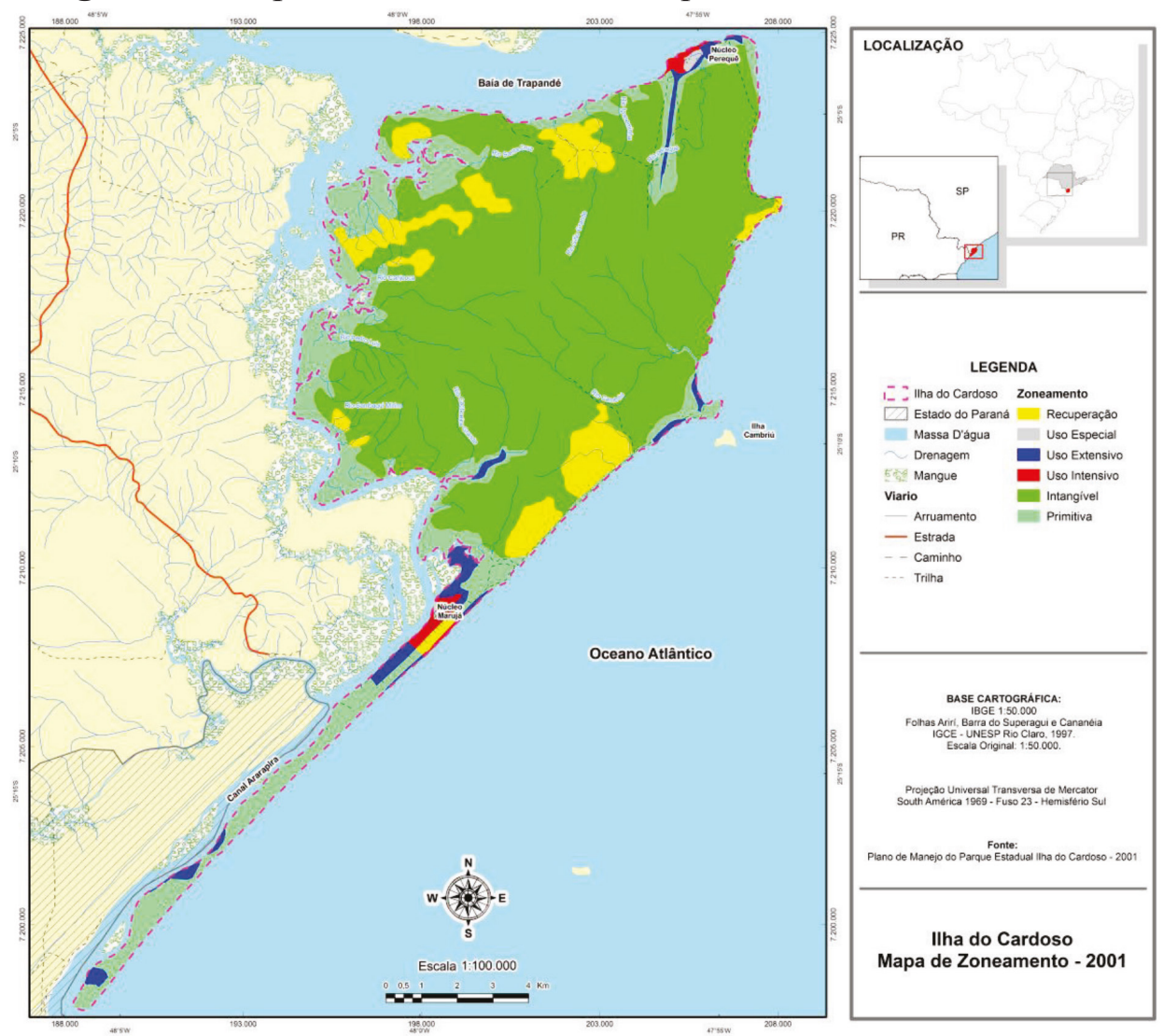

Fonte: Parque Estadual Ilha do Cardoso (2012).

\section{Discussão dos Resultados}

A atual organização territorial e estratégias de manejo do PEIC começou a ser desenvolvida durante a Fase 2 do Plano de Manejo e passou por mudanças complexas até atualmente. O plano de manejo do PEIC foi viabilizado através da implementação do Projeto de Preservação da Mata Atlântica (PPMA

resultado de uma cooperação financeira internacional entre o Brasil e a Alemanha, pelo Governo do Estado de São Paulo e do Banco Kreditanstalt fur Wiederaufbau (KfW). 
Jéssica de Lima Silva, Regina Célia de Oliveira. Os modelos de organização territorial e gestão das áreas protegidas do litoral de São Paulo com enfoque no Parque Estadual Ilha do Cardoso

O PPMA abrange uma região de $22.000 \mathrm{Km} 2$, que vai de norte a sul do litoral do estado, compreendendo as áreas no Vale do Paraíba e no Vale do Ribeira, respectivamente.

As principais definições que ocorreram na Fase 2 do plano de manejo se referiram à administração, visitação pública/educação ambiental, proteção, pesquisa, apoio à regularização fundiária e fronteiras. As ações voltadas para organização e incentivos turístico estavam na pauta dessa Fase 2, e o estabelecimento de diretrizes e normas relacionados à presença de moradores tradicionais no interior da UC também estavam no foco da elaboração dessa fase.

Foi realizada uma classificação em cinco grupos de residentes do PEIC, desde os moradores até os turistas, divididos em:

Grupo I: moradores tracionais residentes; grupo II: moradores tradicionais não residentes; grupo III: moradores adventícios antigos; grupo IV: caseiros; grupo V: turistas.

No grupo I enquadram-se a maior parte dos "sítios" dispostos na face estuarina, desde o Itacuruçá (que compreende o núcleo Perequê) ao norte da Ilha, até os limites com o núcleo Marujá, ao sul da Ilha. Os moradores tradicionais do núcleo Perequê ali vivem há pelo menos três gerações de famílias. No mapa de Zoneamento do PEIC (Figura 2), todos os Núcleos de moradores enquadram-se nas Zonas de Uso intensivo e Extensivo do PEIC.

As atividades turísticas do PEIC foram reorganizadas a partir dos anos 2000, quando se propôs uma gestão participativa no núcleo Marujá, na qual os moradores tiveram relativa autonomia para organizarem entre si as delegações de tarefas e ações para promoverem o turismo nesse núcleo.

Durante a implantação da fase 2 do plano de manejo, a gestão participativa surtiu efeitos, principalmente no Núcleo Marujá. Houve um esforço de se trabalhar em conjunto com a comunidade desse núcleo e muitos moradores se tornaram monitores ambientais (também no núcleo Perequê), tendo se organizado para a recepção de turistas e grupos escolares que frequentam o Parque nos períodos letivos do ano.

A atividade mais rentável no Marujá se deu com a organização do turismo, do ponto de vista de recepção e infraestrutura. Em entrevista com morador do núcleo Marujá, o mesmo afirma que, com o incentivo do turismo crescente e desordenado na década de 1980 e 1990 no Parque, foi necessário que os moradores se organizassem e promovessem 
uma autogestão local, corroborada posteriormente com a Fase 2 do plano de manejo.

Foram então organizadas, por ele e a Associação de Moradores na época, várias reuniões, debates, para chegarem a um consenso sobre os rumos que o Marujá tomaria, bem como outros Núcleos, mas cada um com seus interesses e particularidades em questão. As opiniões e considerações dos moradores desse núcleo são muitas vezes divergentes - muitos moradores caiçaras que vivem da pesca relataram não se reconhecer nos outros caiçaras e nos grupos tradicionais que exploram a atividade turística sem maiores questionamentos. Por outro lado, para outros as restrições das atividades agrícolas é algo essencialmente prejudicial, ao passo que para os adeptos do turismo não é algo determinante em suas vidas.

Essa é uma questão que exprime territorialidades múltiplas por parte das próprias populações que vivem nesses núcleos. Neste sentido, o significado do que é "ser" caiçara de acordo com os moradores tem tomado novos rumos com o advento das atividades turísticas e cerceamento das possibilidades de reprodução dos seus territórios após a proibição das atividades agrícolas, pois a cultura caiçara está intimamente ligada ao seu modo de produção com a terra e o mar.

Atentando para outros Núcleos, no caso o Núcleo Perequê, os moradores viviam fundamentalmente da pesca realizada na área estuarina, sendo que nas últimas décadas o turismo foi incorporado de forma expressiva no local. Porém, somente após a década de 2000 que as atividades turísticas passaram a ser (de fato) basicamente organizadas. No entanto, ainda hoje, o Núcleo Perequê sofre com problemas relacionados ao turismo de "orla" do estuário, em função de estar localizado muito próximo a Cananéia, o acesso praticamente livre a ele por turistas que visam aproveitar o dia na "praia" e assim dirigem-se ao núcleo Perequê, apenas nesse sentido.

A infraestrutura desse núcleo para o turismo é bem menor em relação ao Marujá - possui dois restaurantes e alguns moradores possuem áreas de camping, principalmente porque a finalidade dos turistas que o visitam não é realmente dormir no local ou passar dias (como no Marujá).

Nos finais de semana, feriados e alta temporada, porém, o núcleo Perequê tem sua orla estuarina praticamente toda ocupada por turistas. Apenas duas famílias são donas dos restaurantes e, portanto, incorporaram essa atividade comercial. Outros trabalham em Cananéia e devido à 
Jéssica de Lima Silva, Regina Célia de Oliveira. Os modelos de organização territorial e gestão das áreas protegidas do litoral de São Paulo com enfoque no Parque Estadual Ilha do Cardoso

proximidade retornam ao Parque no fim do dia, além dos que são monitores ambientais e os que vivem da pesca.

Esse Núcleo possui uma área destinada ao alojamento de pesquisadores e estudantes que realizam desde trabalhos de campo e experiências no local, até pesquisas e estudos específicos sobre a Ilha do Cardoso. Em relação aos Núcleos da Enseada da Baleia e Vila Rápida, lá vivem 9 famílias e 7 delas vivem essencialmente da pesca. As outras duas hospedam turistas em suas casas e possuem um restaurante para atender aos turistas na Enseada da Baleia. Esse Núcleo recebe muitos turistas num feriado específico do ano, quando se realiza a "Festa da Baleia" - também conhecida com a "Festa do Padroeiro São Sebastião - e em outros feriados. O maior problema no local, atualmente, é que processos erosivos atuantes há muitos anos no local estão avançando rapidamente em direção aos núcleos - há casas que já foram destruídas pelos processos erosivos e as outras construções estão sujeitas a tal processo.

Os moradores há anos pedem medidas mitigadoras de contenção parar retardar o avanço dos processos erosivos nesse Núcleo. Contudo os próprios moradores se organizaram para colocar barreiras de contenção nas construções mais ameaçadas. Quanto à possibilidade de realocação para outros Núcleos, visto que novas construções teriam que ser feita nesse caso, não é algo em cogitação segundo o geólogo do Conselho Gestor do PEIC.

A cerca de $10 \mathrm{~km}$ da Enseada da Baleia, no pontal do Leste, ao extremo sul da ilha, as poucas famílias residentes vivem fundamentalmente da pesca, com exceção nos períodos de dezembro a fevereiro, quando recebem turistas para as festas de fim de ano e carnaval. Por estar localizado no extremo sul da Ilha, sendo o ponto mais distante da Ilha em relação à Cananéia, de onde geralmente partem os turistas em direção ao PEIC, a procura de turistas é relativamente baixa se comparada ao Núcleo Maruja.

Está em processo de desenvolvimento pelos membros da Associação de Moradores do Marujá uma proposta de recategorização do Núcleo Maruja, para passar de integrante de Parque Estadual para integrante de uma RDS (Reserva de Desenvolvimento Sustentável). Porém, ainda é algo introdutório e sem a oficialização perante o Conselho Gestor do Parque. A opinião dos moradores de outros núcleos é dividida, pois além de não estarem articulados em relação à proposta, caso ela viesse a ocorrer, beneficiaria somente o Núcleo Marujá, a menos que outros, com o Perequê, também com potencial 
turístico, embora em menor escala, fosse incorporado. Uma das maiores reivindicações para a criação da RDS, além de flexibilizar as atividades turísticas, é que na mesma o Conselho Gestor é deliberativo e, assim, os membros do Conselho deste Núcleo teriam maior autonomia e poder de decisão.

Visto a importância do papel do Conselho Gestor no PEIC, um fato notório e preocupante é a ocorrência de elevada rotatividade da equipe gestora nos últimos anos, reflexos das mudanças e direcionamentos da Fundação Florestal. O maior registro de um só gestor no Parque é de quase sete anos quando houve a elaboração da Fase 2 do Plano de Manejo.

Em maio de 2014, foi aprovada a Portaria FF/DE Nº93/2014 que dispõe sobre a Criação do Grupo de Trabalho para elaboração da proposta de criação de Programa de Governo para o reassentamento das populações tradicionais em UC nas quais sua permanência não seja permitida (Art.1). O Grupo de Trabalho se deu por representantes das seguintes áreas: dois representantes do Núcleo de Regularização Fundiária, dois representantes da Diretoria Litoral Norte e Diretoria Litoral Sul, um do Núcleo Metropolitana e Interior, um da Assessoria Jurídica e por cinco membros do ITESP.

A notícia repercutiu com preocupação entre os moradores do PEIC, visto que até junho deste ano, o Conselho Gestor ainda não havia se manifestado nas reuniões com os moradores para esclarecer como o Grupo de Trabalho em questão está trabalhando em relação às questões de um possível reassentamento no PEIC. Segundo Membros da Associação de Moradores do Núcleo Perequê e Marujá, os residentes de UC do Vale do Ribeira estão cientes dos objetivos da nova Portaria em priorizar a questão fundiária nas UC com vistas ao reassentamento, e as ações deste Grupo de Trabalho devem ser oficializadas nos próximos meses em relação ao que é estabelecido pela Portaria.

No caso do PEIC, o estabelecimento do território político de proteção da natureza, neste caso, vem causando novas demandas e preocupante cerceamento da possibilidade de produção dessas territorialidades, provocando o enfraquecimento dos seus modos de vida tradicionais. Em contrapartida, na ausência de muitas dessas UC, muitos destes remanescentes hoje conservados, possivelmente, não existiriam mais. Uma das consequências disto foi que muitas populações tradicionais tiveram proteção em função da existência destas áreas protegidas. 
Jéssica de Lima Silva, Regina Célia de Oliveira. Os modelos de organização territorial e gestão das áreas protegidas do litoral de São Paulo com enfoque no Parque Estadual Ilha do Cardoso

Diegues (2001) reconhece que em muitos casos a criação de unidades de conservação protegeu os moradores tradicionais contra a especulação imobiliária galopante e a expropriação de suas terras. No entanto, foram severamente tolhidos de exercer suas atividades no interior destas áreas e não podiam ter acesso a serviços básicos e nem exercer suas atividades de plantio, muitas vezes, seus meios de sobrevivência.

No PEIC, a grande rotatividade no Conselho Gestor ao longo dos anos, é um fator que tem dificultado ações e estratégias de gestão com resultados efetivos. Esse foi um dos pontos fundamentais abordados por dois antigos gestores. Ambos relataram que a inconstância institucional da Fundação Florestal tem contribuído para a crise na Gestão das UC no estado, conforme já apresentado neste estudo.

Os princípios de Gestão Participativa do Uso Público no PEIC, advindos do Plano de Manejo Fase 2, são considerados avanços importantes no que tange à gestão participativa, tanto pela comunidade do Núcleo Marujá quanto pelo Conselho Gestor da época. Embora a equipe gestora tenha sofrido mudanças nesses últimos anos, o turismo de base comunitária e gestão participativa de uso público no Marujá fundamentalmente se mantêm. Contudo, nos outros Núcleos os princípios dessa gestão participativa têm ocorrido com uma frequência menor nos últimos anos, segundo os moradores e os próprios representantes dos Núcleos no Conselho.

A comunidade do Núcleo Maruja internalizou o processo participativo de ordenamento de visitação pública e de socialização dos recursos, consolidando o turismo de base comunitária, e vem desenvolvendo melhorias para a qualidade do receptivo turístico. Mesmo o PEIC não dispondo de número adequado de funcionários direcionados a atividade de ordenamento de visitação pública e fiscalização, vem conseguindo viabilizar o segmento da atividade e controle desta, por meio do processo de gestão participativa do ordenamento turístico, principalmente no Núcleo Marujá.

Porém, nos outros Núcleos que aderem ao turismo, o nível de organização e infraestrutura para o desenvolvimento deste segmento é bem menos expressivo e a preocupação em relação às questões referentes à regularização fundiárias e permanência são tidas como preocupação maior dos moradores. Nesse sentido, a criação de uma RDS no Núcleo Marujá, como está em vias de proposta, poderia configurar uma boa alternativa para a população tradicional que ali vive. 
É necessário, porém, pensar também nas questões de reassentamento prevista nesta Portaria, em relação aos outros Núcleos que não seriam contemplados pela RDS, caso esta viesse a se tornar realidade. O PEIC se destaca pela biodiversidade ali existente e, portanto, por agregar espaços de relevante heterogeneidade. Suas características físicas e bióticas representam um dos biomas mais importantes em nosso planeta, fazendo com que a tarefa de conserva-lo não só se justifique, mas seja necessária por parte do poder público, pois os fragmentos de Mata Atlântica ainda restante se esvaem com rapidez da superfície terrestre.

Compreende-se, com isso, que o papel do Conselho Gestor é de elevada importância, visto que são incumbidos de efetivar os objetivos de conservação da biodiversidade existente no PEIC. Os esforços por parte do Conselho Gestor em trabalhar com fundamentos da Gestão Participativa tem demonstrado resultados importantes no que diz respeito ao trabalho em conjunto entre as comunidades e a equipe de Gestão.

As comunidades tradicionais caiçaras expressam suas territorialidades através da sua própria persistência em continuar residindo na Ilha, mantendo suas tradições e modos de vida. As expressões territoriais se fazem notar também nas percepções paisagísticas das populações tradicionais e do Conselho Gestor, nas quais o simbólico fica exposto no material e os modos de vida e de visão das realidades das populações tradicionais se evidenciam.

Concluindo, tem-se que a conservação do PEIC pode ter maior efetividade a partir do momento em que se relativizam as distâncias entre os interesses e perspectivas dos atores das UC e o Conselho Gestor, no sentido de promover a efetiva conservação da biodiversidade presente nesta UC. Nesse sentido, considerar as estratégias de Manejo e Gestão Participativa, é um ponto de partida para as populações tradicionais, que reivindicam o direito de permanência no interior do Parque sob o fundamento de garantia da manutenção dos seus modos de vida tradicionais e garantia de preservação de sua diversidade cultural.

Sobre algumas breves considerações a respeito das Políticas ambientais aqui apontadas, o cenário referente às Unidades de Conservação brasileiras historicamente refletiu muitos conflitos entre os interesses de conservação da biodiversidade e os interesses das populações tradicionais 
Jéssica de Lima Silva, Regina Célia de Oliveira. Os modelos de organização territorial e gestão das áreas protegidas do litoral de São Paulo com enfoque no Parque Estadual Ilha do Cardoso

que habitam a maior parte destas áreas protegidas, como é o caso das UCs de Proteção Integral.

Muitas lacunas presentes nas políticas ambientais que dificultam a efetividade das UCs nos seus propósitos são muitas vezes decorrentes do próprio processo de construção das propostas de criação de áreas protegias no Brasil, pois, em diferentes momentos políticos, procurou atender às demandas e propostas mais imediatas da corrente conservacionista no Brasil.

Um dos principais desafios ainda consiste em estabelecer com maior precisão a integração das áreas protegidas com as diferentes escalas de planejamento (um exemplo a ser citado são que os Mosaicos e também os corredores ecológicos), gestão do território e esferas do poder público (Federal, Estadual e Municipal).

Medeiros (2006) aponta que umas razões para a culminância deste processo - a instituição do SNUC - não ter ainda conseguido contemplar em definitivo uma solução para todos os problemas relacionados à baixa integração e gerenciamento destas áreas, se dá em razão da falta de consenso político, sobretudo, em relação aos problemas e desafios de integração das UCs. De fato existem indicadores que historicamente nos meios científicos e institucionais das políticas ambientais no Brasil, ocorrem batalhas políticas e ideológicas e as populações tradicionais, sejam indígenas, caiçaras, quilombolas, ribeirinhos, muitas vezes parecem ter entrado na linha de fogo.

Assim, os esforços na política brasileira para construir uma agenda integrada que traga debates sobre as áreas protegidas, foram liderados pela Diretoria de Áreas Protegidas do Ministério do Meio Ambiente a partir de 2003, que reconheceu sendo os principais impasses que ocorrem negativamente nas UCs, os conflitos e tensões ainda existentes nas áreas de contato entre UCs, terras indígenas, terras devolutas, passíveis de grilagem e especulação e a falta de políticas de Gestão integrada no caso das UCs com populações tradicionais residentes.

A ineficiência e/ou não atuação do governo na desocupação das áreas protegidas (quando iniciou a criação destas no Brasil) ou realocação das famílias teve um significado muito forte para os socioambientalistas: uma estratégia de congelar as áreas, cerceando as possibilidades de reprodução dos territórios das populações tradicionais, forçando- as a saírem destes locais. A inoperância e mesmo a demora em definir as políticas de regularização fundiária adequadamente nessas unidades, priorizando apenas a criação de 
parques para posteriormente definir como seriam manejados tiveram sérios efeitos e consequências para as populações residentes nestas áreas.

Em contrapartida, na ausência de muitas dessas UCs, muitos destes remanescentes hoje conservados, possivelmente, não existiriam mais. Uma das consequências disto foi que muitas populações tradicionais tiveram proteção em função da existência destas áreas protegidas.

Dentre muitos pontos de discussão em relação às políticas ambientais sobre áreas protegidas e os atores presentes nas mesmas, vários emergem como alternativas possíveis para a potencialização dos processos de conservação da natureza em Parques e minimização dos impactos econômicos sobre a biodiversidade. Dentre eles, o investimento em gestões de UCs com caráter participativo e implantação de políticas de inserção de turismo de base comunitária. Essas alternativas são consideradas muitas vezes efetivas, no contexto de fazer cumprir o papel das áreas protegidas e também como oportunidade de inclusão das populações consideradas tradicionais.

Irving (2002), coloca que as áreas protegidas têm um papel fundamental para a proteção de espécies e de diversidade genética e manutenção dos ecossistemas, mas também para o sustento das populações tradicionais.

Diegues (2004) atenta para o fato de ser necessário dar novos rumos e orientações às políticas ambientais brasileiras e as formas como estão estabelecidas essa relação dicotômica entre parques e comunidades que persiste ainda hoje num contexto mundial, sobretudo nos países com grandes contingentes de populações vivendo em UCs. De modo que ao invés de permanecerem as discussões sobre os conflitos em áreas protegidas decorrentes dessa relação dicotômica, há outra possibilidade, que é a de construir junto com as populações tradicionais uma relação que possibilite a conservação da biodiversidade e que sejam economicamente eficazes.

Trata-se, portanto de valorizar a identidade, os conhecimentos, as práticas e os direitos de cidadania destas populações, valorizando seu padrão de uso e manejo dos recursos naturais e legitimando as contribuições que historicamente essas populações realizaram. Isto não significa não reconhecer que se trata de uma relação complexa a presença humana em áreas protegidas e claramente não se deve generalizar ou superestimar o papel das populações tradicionais.

As Áreas Protegidas, de acordo com as suas especificações de Categorias de Manejo, sejam de Proteção Integral ou de Uso Sustentável, 
representam atributos únicos e relevância do ponto de vista ecossistêmico, os quais tornam as Paisagens ali constituídas, suas funções ambientais e consequentemente, a relevância da biodiversidade, únicas, portanto, apresentam atributos físicos e muitas vezes socioculturais, que raramente ocorrem em outros lugares, sendo específicos destas áreas.

Os sistemas de áreas protegidas são conhecidos como arranjos e instrumentos institucionais essenciais na articulação e implementação de estratégias e gestão de conservação e de desenvolvimento territorial sustentável, sendo considerados partes fundamentais da resposta mundial no combate aos graves cenários de degradação da biodiversidade que presenciamos num contexto global.

Nesse sentido, os conhecimentos tradicionais sobre a natureza e os territórios onde comunidades tradicionais, como indígenas, caiçaras, quilombolas e outros grupos sociais locais desenvolvem e fazem uso dos recursos naturais, apresentam uma inegável importância ao aumento da resiliência dos ecossistemas, contribuindo com a manutenção da provisão de bens e serviços que beneficiam as comunidades tradicionais, a economia local e o cumprimento dos objetivos das áreas protegidas, de efetiva conservação da biodiversidade restante.

Ficam, portanto, os questionamentos sobre as políticas de conservação e suas atuações e interesses, é evidente a existência de diferentes atores atuantes sobre as UCs e seus distintos projetos para elas.

\section{Referências}

AB'SABER, A.N. O Ministério do Meio Ambiente tem errado em quase tudo (entrevista concedida a Maria Eduarda Mattar). La Insignia. (disponível em http://www.lainsignia.org/2005/mayo/ibe 056.htm Aziz Ab`Saber

(17 de Maio de 2005), acessado pela última vez em 03/05/2014.

ARAUJO, M. A. R. Unidades de Conservação no Brasil - o caminho da Gestão para resultados. RiMa Edtitora: São Carlos, 2012.

BENJAMIN, A. H. Introdução à Lei do Sistema Nacional de Unidades de Conservação. In: Meio Ambiente, Direito e Cidadania, PHILIPPI Jr, A. São Paulo: Universidade de São Paulo. Faculdade de Saúde Pública, Faculdade de Direito, Faculdade de Arquitetura e Urbanismo, Núcleo de Informações em Saúde Ambiental: Signus Editora, 2002. p.235-266. 
BRASIL. Presidência da República. Comissão Interministerial para a Preparação da Conferência das Nações Unidas sobre o Meio ambiente e Desenvolvimento. Desafios do desenvolvimento Sustentável. Brasília: Cima, 1991.

BRASIL. Lei $n^{0} 9.985$ de 18 de julho de 2000. Diário Oficial da República Federativa do Brasil. Brasília, 19 de jul. 2000. Seção I. p. 12026-12027

BRASIL. Código Florestal. Lei n ${ }^{\circ} 4.471$ de 15 de setembro de 1965. Disponível em: <http://www.planalto.gov.br/ccivil_03/LEIS/L4771. $\underline{\mathrm{htm}}>$. Acesso em: 01 de nov. de 2010.

BRASIL. MMA. Plano Nacional de Áreas Protegidas. Brasília: MMA/Sec. de Biodiversidade e Florestas/Diretoria de Áreas Protegidas, 2006.

CASTRO, C. E. A Política Nacional de Proteção da Natureza e seus Desdobramentos no Território do Parque Nacional dos Lençóis Maranhenses. Tese de Doutorado, FCT/UNESP, Presidente Prudente, 2012.

CNRBMA. Conselho Nacional da Reserva da Biosfera da Mata Atlântica. Sistema Nacional de Unidades de conservação: texto da Lei 9.985 de 18 de julho de 2000 e vetos da presidência da República ao PL aprovado pelo Congresso Nacional. 2ed. revista e ampliada. São Paulo: CNRBMA, 2002.

CROCETTI, M. TERRA DE NINGUÉM? Entrevista com Tasso Azevedo. Revista EcoTerra Brasil, 2004. Disponível em: <http://www.ecoterrabrasil.com.br/home/index.php?pg=ecoentrevistas\&tipo=temas\& $\underline{\mathrm{cd}=78}>$ Acessada pela última vez em 20-07-2014

DECRETO n. 6040 de 7 de fevereiro de 2007 que institui a Política Nacional de Desenvolvimento Sustentável dos Povos e Comunidades Tradicionais.

DECRETO n. 5758 de 13 de abril de 2006, que institui o Plano Estratégico Nacional de Áreas Protegidas, seus princípios, diretrizes, objetivos e estratégias e dá outras providencias.

DIEGUES, A.C. Saberes tradicionais e etnoconservação. In: DIEGUES, A. C.; VIANA, V. M. Comunidades tradicionais e manejo dos recursos naturais da Mata Atlântica. São Paulo: NUPAUB/LASTROP, 2004. p.9-22.

DIEGUES, A.C. A ecologia política das grandes ONGs transnacionais conservacionistas. NUPAUB-USP, 2008.

DIEGUES, A. C.; ARRUDA, R. S. V. (Org.). Saberes tradicionais e biodiversidade no Brasil. Brasília, DF: Ministério do Meio Ambiente; São Paulo: USP, 2001. 176 p. 
Jéssica de Lima Silva, Regina Célia de Oliveira. Os modelos de organização territorial e gestão das áreas protegidas do litoral de São Paulo com enfoque no Parque Estadual Ilha do Cardoso

FERREIRA, L. C. Conflitos sociais em Áreas Protegidas no Brasil: moradores, instituições e ONGs no Vale do Ribeira e Litoral Sul, SP. Idéias. 8 (2). 2001.

FRÓIS, C. Projeto paulista legaliza concessões em parques estaduais. "O eco", 2014. Disponível em: <http://www.oeco.org. br/reportagens/27999-projeto-paulista-legaliza-concessoes-emparques-estaduais $>$. Acessado pela última vez em: abril de 2014.

INSTITUTO SOCIOAMBIENTAL - ISA. Almanaque Brasil Socioambiental. São Paulo: Instituto Socioambiental, 2005.

IRVING, M. A. Refletindo sobre a Relação entre Proteção da Natureza e Ecoturismo em áreas protegidas: tendências no contexto brasileiro. IRVING \& AZEVEDO (Orgs.)Turismo o desafio da Sustentabilidade. São Paulo: Editora Futura (2002).

IUCN. Guidelines for Protected Areas Management Categories. Cambridge, United Kingdon and Gland, Switzerland: IUCN, 1994. 29 p.

IUCN.. Protected Areas Programme. Parks. The international journal for Protected Area managers. Published of the World Commission on Protected Areas (WCPA) of the IUCN - World Conservation Union. sd.

MEDEIROS, R. Evolução das tipologias e categorias de áreas protegidas no Brasil. Ambiente \& Sociedade. V.9.1 (2006): 41-64.

PADUA, M. T. J. Unidades de Conservação: muito mais do que atos de criação e planos de manejo. In: Miguel Sereduik Milano (org.) Unidades de Conservação: Atualidades e Tendências. Curitiba: Fundação O Boticário de Proteção à Natureza, 2003.

SANTILLI, J. Povos indígenas, quilombolas e populações tradicionais: a construção de novas categorias jurídicas. In: Ricardo, Fanny (org). Terras indígenas e Unidades de Conservação na natureza: o desafio das sobreposições. São Paulo: Instituto Socioambiental, 2005.

VALLEJO, L. R. Unidades de conservação: uma discussão teórica à luz dos conceitos de território e de políticas públicas. 2010. Disponível em: <www.uff.br/geographia/ojs/index.php/geographia/article/.../88>. Acessado pela última vez em: 12 de out. 2011.

VIANNA, L. P. De invisíveis a protagonistas - populações tradicionais e unidades de conservação. Anna Blume Editora: São Paulo, 2008. 
